Recepción: 16/04/2015

Evaluación: 18/04/2015

Aprobación: 20/06/2016

Artículo de Revisión

\title{
DE LA ESCUELA NORMAL SUPERIOR DE COLOMBIA AL INSTITUTO CARO Y CUERVO. UN APORTE HISTÓRICO CULTURAL A LA EDUCACIÓN COLOMBIANA (1936-1951)*
}

\author{
Claudia Figueroa \\ Universidad Pedagógica y Tecnológica de Colombia \\ Grupo de Investigación: "Historia y Perspectiva de la Universidad Latinoamericana". HISULA \\ claudiafig2@hotmail.com \\ Carlos Arturo Londoño Ramos \\ Universidad Pedagógica y Tecnológica de Colombia \\ Grupo de Investigación: "Historia y Perspectiva de la Universidad Latinoamericana". HISULA \\ londonocarlosarturo@hotmail.com
}

\begin{abstract}
RESUMEN
Este artículo tiene como objetivo primordial presentar los intercambios entre la Escuela Normal Superior y el Instituto Caro y Cuervo, como vigía y difusor del patrimonio lingüístico y lexicográfico de Colombia. El Instituto Caro y Cuervo se relacionó con la Escuela Normal en cuanto a profesores, estudiantes, pensum y trayectoria científica en el estudio del legado histórico-cultural del el País.

Palabras clave: Escuela Normal Superior, Instituto Caro y Cuervo, lexicografía, filología.
\end{abstract}

\footnotetext{
* Este artículo es resultado de la investigación sobre "La Escuela Normal Superior de Colombia y sus institutos anexos (1936-1951)".
} 


\title{
THE NORMAL SUPERIOR SCHOOL OF COLOMBIA AND THE CARO Y CUERVO INSTITUTE. A CULTURAL HISTORICAL CONTRIBUTION TO COLOMBIAN EDUCATION (1936-1951)
}

\begin{abstract}
The main objective of this article is to present exchanges between the Ecole Normale Supérieure and the Caro and Cuervo Institute as viewed and disseminated by the lexicographical and linguistic patrimony of Colombia. The Caro and Cuervo Institute relates to the Normal School in that teachers, students, curricula and scientific careers are geared toward the study of the historical and cultural heritage of the country.
\end{abstract}

Key words: Normal Superior School (Ecole Normale Supérieure), Caro and Cuervo Institute, Philology, Lexicography.

\section{DA ESCOLA NORMAL SUPERIOR DA COLÔMBIA AO INSTITUTO CARO Y CUERVO. UMA CONTRIBUIÇAO HISTORICA CULTURAL À EDUCAÇÃO COLOMBIANA (1936-1951)}

\begin{abstract}
RESUMO
Este artigo tem como principal objetivo apresentar os intercâmbios entre a escola Normal e do Instituto Caro y Cuervo, como um vigia e disseminador do património lexicográfico e linguística da Colômbia. 0 Instituto Caro y Cuervo se relacionou com a Escola Normal como professores, estudantes, currículo e trajetória científica no estudo do legado histórico e cultural do país.
\end{abstract}

Palavras-chave: Escola normal Superior, Instituto Caro y Cuervo, Lexicografia, filologia. Capuchinhos. 


\section{INTRODUCCIÓN}

Este artículo tiene como objetivo primordial analizar los aportes e intercambios entre la Escuela Normal Superior y el Instituto Caro y Cuervo, como vigía y difusor del patrimonio lingüístico y lexicográfico de Colombia.

De acuerdo a lo anterior, en el marco de la investigación se hizo necesario preguntarnos Cuáles fueron los intercambios que se dieron entre la Escuela Normal Superior y el Instituto Caro y Cuervo que permitieron articular la academia y su propia trayectoria desde un legado histórico cultural.

El hecho más significativo en la historia de Colombia es el significado y proyección del Instituto Caro y Cuervo y su relacionó con la Escuela Normal Superior en cuanto a profesores, estudiantes, currículo y trayectoria científica en el estudio del legado histórico-cultural del país.

Para ello se tuvo en cuenta la metodología de la historia social y de las instituciones educativas como base fundamental la historia de la educación, soportado en los archivos encontrados en la Facultad de Ciencias de la Educación de la Universidad Pedagógica y Tecnológica de Colombia sobre la Escuela Normal Superior en Bogotá y el Fondo Posada de la Biblioteca Jorge Palacios Preciado de esta misma institución, el Archivo General de la Nación, el Archivo del Instituto Caro y Cuervo ubicado en la Hacienda Yerbabuena Bogotá y las Bibliotecas más importantes del país.

Es importante reconocer que el nombre del Instituto Caro y Cuervo hace referencia a dos ilustres personajes de la investigación idiomática colombiana de finales del siglo XIX, como fueron: Miguel Antonio Caro y Rufino José Cuervo, quienes comenzaron la creación del Diccionario de construcción y régimen de la lengua castellana, que no terminaron y hubo de ser continuado por la generación del siglo XX, la cual se convirtió en la preocupación de los intelectuales que lideraron estos estudios.

El Instituto Caro y Cuervo es reconocido por el legado las investigaciones científicas en las áreas de lingüística, filología y humanidades con lo cual han efectuado un gran aporte a la construcción de la cultura idiomática de la nación colombiana.

Principalmente, la estructura académica condujo a formar especialistas sobre la base de prácticas en investigación de usos del idioma, la divulgación del patrimonio, recopilación, redacción y traducción de obras literarias. Esta obra se consolidó con los seminarios ofrecidos a investigadores locales, nacionales e internacionales. En especial, se destaca la difusión del conocimiento lingüístico y lexicográfico mediante las obras provenientes de otros países, entre ellos: España, Estados Unidos, Francia, México, Argentina, Chile y Venezuela. Estas obras sirvieron de soporte para la difusión y recepción del conocimiento, y su 
influencia se deriva de su relación con la Academia de la Lengua Española y la Academia Colombiana de la Lengua.

De ahí la importancia de retomar las fuentes historiográficas para conocer su trayectoria histórica en el marco de sus antecedentes y evolución histórica, en especial, el intercambio institucional con la Escuela Normal Superior, de ella egresaron algunos profesores, además de la colaboración académica con la Licenciatura en Filología e Idiomas, la cual formó los educadores de mediados de siglo con un gran sentido humanista y pedagógico y la proyección del Instituto Caro y Cuervo cuyo soporte se desarrolla en los estudios de la filología y la lingüística para conocer la cultura de la nación y su articulación con la educación, lugar apropiado para la formación de especialistas.

\section{DESDE LA LICENCIATURA EN FILOLOGÍA E IDIOMAS EN LA ESCUELA NORMAL SUPERIOR DE COLOMBIA}

La construcción humanística de los licenciados en Filología e Idiomas se sustenta desde la Escuela Normal Superior en Bogotá y se proyecta al Instituto Caro y Cuervo, la cual tiene como objeto el aprendizaje de los idiomas con las mejores ventajas y desarrollos para un momento histórico en que los educadores debían leer y escribir en otros idiomas para fortalecer su aprendizaje, pues la difusión de la cultura hacía de ello una necesidad para que los licenciados o licenciadas lograran un bagaje cultural en todos los idiomas, el mejor apoyo fue la biblioteca, material de apoyo de los educadores, lo cual era imprescindible aprender y comprender múltiples obras. De ahí la importancia de conocer su legado histórico y reflexionar frente a sus orígenes, desarrollo y proyección, de tal forma que las generaciones comprenderían su significado y se identificarían con su propia identidad cultural.

En su estructura académica son significativos los aportes pedagógicos, investigativos y de patrimonio histórico cultural enmarcados en la tercera, cuarta y quinta década del siglo XX y su proyección, hoy Licenciaturas en Idiomas y Leguas Extranjeras, la cual le apuestas a los retos y desafíos del Siglo XXI, los cuales le han aportado a la solución de los problemas educativos, y en general al desarrollo de la cultura nacional, como un propósito justo para la la sociedad en general, a partir de un saber humanístico y cultural del país legado de infinidad de generaciones.

La Licenciatura en Filología e Idiomas de la Escuela Normal Superior en Bogotá desde sus orígenes en 1936, logró impactar en la formación de educadores del país en la tercera, cuarta y quinta década del siglo XX y se proyectó a los estudios en el Instituto Caro y Cuervo. Así mismo, desde la apropiación del saber pedagógico para la formación de educadores contribuyó a la carrera con la articulación en los Idiomas en la Facultad de Educación de la Universidad Pedagógica de Colombia hasta el Siglo XXI, en lo que hoy es la 
Universidad Pedagógica y Tecnológica de Colombia, con una trayectoria que marca el rumbo de los procesos de calidad y se consolida en un programa de altura y acorde con los lineamientos del mundo moderno y los retos de la sociedad dando relevancia a dos carreras que actualmente posee la universidad, entre ellos las Licenciaturas en Idiomas y Leguas Extranjeras, la cual le han aportado muchísimo a los problemas educativos y a la sociedad en general, a partir del saber humanístico y cultural del país para comprender a las múltiples generaciones.

Como escenario de construcción del conocimiento, la Escuela Normal Superior influyó en su estructura académica y como especialidad, dando grandes frutos en la difusión e investigación de la Filología y la Lingüística.

Los aspectos administrativos se enmarcan en la Licenciatura en Filología e Idiomas, impulsada por el rector José Francisco Socarrás, fue organizada mediante el Decreto 1218 de $1938^{1}$ y se mantuvo hasta la llegada a dicho cargo el señor de Guillermo Nannetti. Para su dirección fue nombrado el profesor Gerard Mashur², quien ocupó la posición hasta 1946, cuando el Decreto 527 de ese año determinó que José Francisco Cirre ${ }^{3}$ lo reemplazaría. Sin embargo, este profesor renunció y en septiembre del mismo año, Nannetti propuso ante el Ministerio de Educación al Licenciado Aristóbulo Pardo como candidato al cargo vacante. Por medio del Decreto 2708 fue designado oficialmente este egresado de la Institución, quien permaneció al frente hasta cuando se inició el proceso de disolución de la Escuela.

Uno de los aportes en la formación de educadores es el mismo hecho de que los profesionales en la escuela Normal Superior debían ser humanistas con amplios conocimientos de literatura y de distintas lenguas, capaces de transmitir de manera práctica las características de las grandes escuelas (romanticismo, realismo, simbolismo) y sus respectivos exponentes:

Cabe resaltar que esta carrera fue muy beneficiada por las becas ofrecidas por distintos gobiernos, entre ellos el francés y el británico, para efectuar profundizaciones en áreas como literatura, lengua y fonética inglesas, todas relacionadas con el campo de estudio disciplinar4.

En cuanto a los docentes es significativo reflexionar sobre sus aportes por cuanto su formación y legado confluyeron al conocimiento en sí de este

1. ESCUELA NORMAL SUPERIOR. Archivo Facultad de Ciencias de la Educación de la UPTC, Legajo 37. Folio 203. Decreto número 1218 de 1938 (julio 9).

2. Ibíd., Legajo 36. Folio 301. Comunicado enviado a Gerard Mashur por José Francisco Socarrás Rector octubre 11 de 1938.

3. MINISTERIO DE EDUCACIÓN NACIONAL. Legajo 106. Folio 497. Decreto número 527 de 1946 (febrero 15) .

4. ESCUELA NORMAL SUPERIOR. Archivo Facultad de Ciencias de la Educación de la UPTC. Legajo 100. Folio 576. 
saber específico humanístico, lo más destacado en mencionar es el trabajo de José Francisco Cirre, agregado del Centro de Estudios Históricos de Madrid (Secciones Interamericana y de Filología española), profesor de la Facultad de Filosofía y Letras de la Universidad de Bruselas (Filología y Literatura Española). Llegó a la Escuela en 1939 a Colombia 5 .

Así mimo, el maestro Pedro Urbano González de la Calle: filólogo, lingüista, Doctor en Filosofía y Letras. Arribó a Colombia como una forma de huir de la dictadura franquista. Se vinculó a la Escuela y junto a Félix Restrepo Mejía, consolidó el Instituto Caro y Cuervo, primer centro lingüístico de la Nación ${ }^{6}$, su legado a la cultura colombiana es destacable por lo cual esa semilla que deja es visionada por las generaciones formadas tanto en la Escuela Normal Superior como en el Instituto Caro y Cuervo visible en obras desde su difusión y proyección.

Aristóbulo Pardo, se graduó como licenciado en la Escuela Normal Superior, fue profesor de castellano en la Institución y Director de prácticas en el Instituto Nicolás Esguerra desde 1942. También fue miembro de la Comisión de Folklore Nacional ${ }^{7}$, significó la combinación entre la docencia y el apoyo a la cultura del país, trabajo que realizó con la mayor calidad humana y profesional posible.

El plan de estudios 1938 de esta licenciatura fue reestructurado con el fin de avanzar y conocer la realidad de los pueblos, mediante el estudio de los idiomas empleados en ellos y las obras literarias que hubiesen producido. Para esta carrera, la Literatura fue "el arte por excelencia: en ella se realiza por completo el fin de todas las Bellas Artes"

El artículo 4 del Decreto 1218 de 1938 fijó el plan curricular. Según esta disposición, durante el primer año todas las especializaciones debían abordar pedagogía, francés, inglés, otras áreas que se consideraban básicas y la materia opcional de Música. A partir del segundo año, comenzaban los estudios propios de cada área disciplinar.

Las áreas de gran importancia son el francés, ofrecido desde el segundo año, la cual se destinaban dos horas semanales a diferentes actividades. También se asignaban lecturas colectivas extra clase, seleccionadas por los estudiantes

5. ESCUELA NORMAL SUPERIOR Archivo Facultad de Ciencias de la Educación de la UPTC. Legajo 103. Folio 45. Listado de profesores de la Escuela Normal Superior en Bogotá, 1939. Oficio enviado al señor Guillermo Nannetti por Arthur J. Montaque, noviembre 17 de 1945.

6. Martha Cecilia Herrera y Carlos Low, Los intelectuales y el despertar cultural del siglo. El caso de la Escuela Normal Superior. Una historia reciente y olvidada (Bogotá: Imprenta Nacional, 1994), 45.

7. ESCUELA NORMAL SUPERIOR. Archivo Facultad de Ciencias de la Educación de la UPTC, Legajo 103. Folio 46. Listado de profesores de la Escuela Normal en 1939.

8. Manuel Bonilla, Orientaciones literarias (Ibagué: Tipografía Salesiana, 1936), 95. 
y para cuya apreciación se disponía de la ayuda eventual del maestro ${ }^{9}$. Las didácticas eran variadas, los educadores tenían formas de dar a conocer las temáticas y dinámicas en el aula, la cual se articulaban con la:

- Lectura.

- Gramática.

- Literatura.

- Los parnasianos.

- Teatro y comedia.

- La novela.

- Libros.

Para enseñar el griego era necesaria realizar una práctica tanto oral como escrita, aunque era un curso opcional muchos estudiantes se interesaban por estudiar y hacer este curso, se ofrecía a nivel general a los estudiantes en formación de las Licenciaturas que ofrecía a Escuela Normal Superior, además se orientaba a partir del segundo año y tenía una intensidad de dos horas semanales, con un programa muy estructurado a nivel temático y metodológico y organizado, veamos como se hacía:

Lectura en clase del Libro I: de la Llave del Griego de Félix Restrepo. Comentarios etimológicos, semánticos y gramaticales.

- Declinación.

- Conjugación.

- Sintaxis detallada.

Para aplicar estos fundamentos teóricos se elaboraban trabajos personales sobre Homero, Platón, Sófocles, Eurípides, Aristófanes, Heródoto, Tucídides, Jenofonte y Píndaro, entre otros.

Los seminarios como estrategia, herramienta o como metodología de apoyo a la enseñanza aprendizaje del educador era fundamental, se destaca el aporte a la educación del seminario alemán, entre ellos los altos estudios en Filología y Letras en 1946, seminario de especialización, en los cuales se orientaba literatura francesa, literatura española, literatura colombiana y literatura inglesa en primer semestre, luego se ofreció en segundo semestre se enseñaban con las principales obras, su análisis y discusión de Shakespeare. Profesores: Gordon Bruto y Dorothy Hayes ${ }^{\mathbf{1 0}}$.

En cuanto a los estudiantes de la Licenciatura en Filología e Idiomas se formaron en la ENS entre 1939 y 1945, fueron 47 en comparación de otras

9. Ibíd. Legajo 23. Folio 17. Programa de francés/Sección de Filología e Idiomas, primer año 1937.

10. ESCUELA NORMAL SUPERIOR. Ibíd., Legajo 22. Folio 18. 
licenciatura la cantidad es muy baja, lo cual se destaca que se trató de una Licenciatura poco atractiva, probablemente por su amplio y estricto pensum. De hecho, a quienes optaban por este campo del conocimiento se les consideraba personas de notorias capacidades intelectuales. De 1946 a 1951 la cifra fue prácticamente igual, pues ingresaron 44 alumnos. En este periodo se dio preponderancia al francés y a los seminarios de altos estudios sobre literatura francesa, española y contemporánea.

Los estudiantes eran oriundos de Santander, Valle del Cauca, Antioquia, Cundinamarca (de donde procedía la mayor cantidad), Boyacá, Caldas, Magdalena, Nariño, Chocó y Norte de Santander, entre otros departamentos. En algunas ocasiones se movilizaron para elevar peticiones, como fue el caso de los integrantes de segundo año, quienes el 10 de diciembre de 1939, en correspondencia dirigida al Rector, solicitaron que no se eliminaran las cátedras de griego y latín. Incluso, abogaron por la inscripción de estos cursos en el tercer año del pensum de 1940, para lo cual expusieron varias razones:

1. La Lingüística, como ciencia fundamental de la especialización de idiomas, necesita de las lenguas clásicas (griego y latín) como punto de partida y material para muchas de sus investigaciones.

2. Aceptando que un especialista en lenguas debe conocer ante todo su idioma nativo y que este conocimiento requiere el estudio de las lenguas que gracias a su evolución han constituido el nuevo idioma, es necesario por la fuerza de la realidad referirse en el caso del castellano al latín y al griego.

3. No puede argüirse que solamente el latín haya dado estructura y vida al idioma castellano. Conocido es el alto porcentaje de palabras de nuestro idioma, cuyas fuentes etimológicas se hallan en el griego.

4. El estudio de las lenguas clásicas da más seriedad a la especialización de idiomas y reporta a los que la siguen, ventajas culturales que no es posible menospreciar ${ }^{11}$.

Hay que destacar el papel de los textos y obras leídas por los estudiantes, veamos algunos ejemplos el de Bradelay, en la primera parte el texto presenta un paralelo entre el antiguo inglés, el actual y describe características para establecer comparación con el alemán.

Posteriormente, ofrecía herramientas gramaticales para el aprendizaje del inglés y finalmente presentaba las implicaciones del aprendizaje de una lengua

11. Ibíd., Legajo 43. Folio 79. Correspondencia dirigida al Rector de la Escuela Normal Superior en 1939. Seminario de Cultura americana, 1937. Carta enviada a William Barrien por Lisandro Medrano, diciembre 16 de 1943. 
extranjera, en términos ${ }^{12}$. Obras como las de Mendoza, Antonio Machado, Cauvet Michela Saloti Schnitzle, Berlitz, entre Otros.

En cuanto a los egresados de la Licenciatura en Filología e idiomas, entre 1939 y 1951, esta carrera tuvo una participación del 16\% sobre el total de egresados de la Normal Superior. Ahora bien, en la gráfica 7, se observa que la población masculina fue significativamente mayor en relación con la femenina. Al respecto, es oportuno recordar lo expresado por Herrera y Low, en cuanto al acceso de la mujer a la formación superior: "[...] fue escasa, debido por un lado a la mentalidad tradicional que le había cerrado el paso a la educación femenina durante largo tiempo, y por otro lado, debido a la escasez de mujeres que por la época habían terminados los estudios secundarios, requisito para poder acceder a los niveles de educación superior"13.

Es importante comprender que en la formación de licenciados en Filología e Idiomas fueron más inicialmente el género masculino y se graduaron más que en el género femenino y en el año de 1942 prevalecieron varones, no se matricularon mujeres, en 1943 no se graduó ningún estudiante y en 1944 a 1948, la graduación de las mujeres fueron en un significativo ascenso prevaleciendo los varones, en 1950 llegaron a estabilizarse en un mismo nivel y en 1951 se dispararon los grados de licenciadas mujeres, mientras que los grados de los varones disminuyeron significativamente; esto debido al posicionamiento de las mujeres en los idiomas y lenguas extranjeras.

La pedagogía y evaluación realmente se ve influenciada por los procesos pedagógicos (seminarios, conferencias y prácticas en el Instituto Nicolás Esguerra) la cual se definieron en consonancia con las directrices institucionales y buscaron privilegiar las actividades científicas e investigativas. En cuanto a la evaluación, se siguieron fórmulas más o menos convencionales y tradicionales: exámenes, observación de los directores de grupo y seguimiento al comportamiento de los estudiantes.

Es posible afirmar que la Escuela Normal Superior representó un modelo institucional y pedagógico determinante para la historia de la instrucción docente y la enseñanza superior en el país, pues dio sentido a una revolución educativa caracterizada por la formación de "maestros intelectuales" en diferentes ramas del conocimiento. Estos, como lo expresó en su momento el Rector José Francisco Socarrás:

12 Traducido al español significa: El objetivo del libro es dar a los lectores educados universidad en filología alguna noción de las causas que han producido las excelencias y los defectos de Inglés moderno como un instrumento de expresión. Henry Bradley, The Making of English (London: MacMillan, 1937), 5.

13. Martha Cecilia Herrera y Carlos Low, Los intelectuales y el despertar cultural del siglo. El caso de la Escuela Normal Superior. Una historia reciente y olvidada (Bogotá: Imprenta Nacional, 1994), 49- 50. 
Estuvimos de acuerdo que el pedagogo requiere dominar una ciencia cualquiera a fin de que conozca y se familiarice con el método científico. Rechazamos que fuera la psicología, por considerar que ella no presenta todavía la estructura y solidez de las ciencia sociales o de las biológicas, la química, la física y la matemáticas [...] concluimos que la pedagogía, la psicología y la práctica pedagógica debían ser obligatorias en todas las secciones, en vista de formar no solo profesores especialistas, sino también buenos maestros o sea como expertos en pedagogía con el dominio de una rama científica determinada. Para reforzar la humanística se agregó filosofía e historia del arte en todas las secciones, considerando que el dominio del método científico requiere de la lógica y la teoría del conocimiento y que la información artística amplia el horizonte intelectual del maestro ${ }^{\mathbf{1 4}}$.

Fue así como los maestros se formaban para alcanzar una nueva dimensión humana, abordando la ciencia en su totalidad, la indagación del entorno social, político y cultural a través de vías democráticas y cognoscitivas, de la observación, el análisis y las reflexiones de situaciones concretas. Además, fue una experiencia que propició la aparición y diversificación de múltiples productos relacionados con el quehacer académico: periódicos, revistas, libros, máquinas, material para laboratorio y bibliotecas. Su reconocimiento y utilización constituyó otra contribución al desarrollo económico, social y cultural del país.

Por otro lado, en el recorrido hacia su profesionalización, los aprendices pasaban por evaluaciones de varios tipos, diseñadas para verificar el entendimiento y la apropiación de conocimientos. Estas pruebas podían ser orales, en las cuales se daba respuesta a un interrogante relacionado con el ejercicio cotidiano de la docencia, o se presentaban informes de trabajos personales o grupales. Para la calificación de estos últimos, se confería relevancia al tratamiento de temas novedosos que no habían sido revisados suficientemente en las clases.

En los exámenes escritos, se resolvían cuestionarios o interrogantes sobre problemas disciplinares con el fin de demostrar si el aprendizaje había sido satisfactorio y se lograban ciertos resultados puntuales esperados por el profesor. Ya fueran parciales o totales, diagnosticaban la comprensión e idoneidad alrededor de los ejes temáticos integrantes de las asignaturas estudiadas. En todas estas evaluaciones "se valoraba el rendimiento escolar y el desarrollo de trabajos personales y en grupo de los alumnos, teniendo en cuenta las teorías y la prácticas dirigidas a la investigación"15. La forma de calificar conservó el sistema y la escala tradicional: se asignaban notas de

14. José Francisco Socarrás, Facultad de Educación y Escuela Normal Superior: Su Historia y aporte Científico, Humanístico y Educativo (Tunja: La Rana y el Águila, 1987), 33.

15. Según lo indicado por el Ministerio de Educación Nacional en la Resolución 576 de septiembre 5 de 1938. 
acuerdo con la valoración hecha por el titular de la materia, de tal modo que con una cifra superior a 4 se aprobaba, se aplazaba con dos (3) y se reprobaba con dos (2).

En cuanto a la investigación y extensión el quehacer investigativo, un buen número de egresados se dedicaron profesionalmente a los estudios sobre la lengua castellana:

Algunos siguieron la ruta de los estudios que apasionaban al maestro Pedro Urbano: los estudios lexicográficos de la lengua española, el estudio de la obra de Rufino José Cuervo y la continuidad de su proyecto de sistematización del 'Diccionario de Régimen y Construcción de la Lengua Española'; también los estudios regionales y etnolingüística ${ }^{\mathbf{1 6}}$.

El interés de la Escuela por las investigaciones de esta Licenciatura se evidencia en algunas comunicaciones remitidas por el Secretario General, Lisandro Medrano, a Estados Unidos, país donde egresados y estudiantes desarrollaban trabajos científicos. Así, en una de ellas se calificaba de "especialmente interesante" que uno de los alumnos lograra "redondear sus estudios sobre lenguas aborígenes de América del Sur"17.

Destacados profesores como el Padre Félix Restrepo y Pedro Urbano González de la Calle, también se dedicaron a la investigación. Estos intelectuales realizaron trabajos filológicos, continuaron la monumental obra del Diccionario de construcción y régimen de la lengua española ${ }^{\mathbf{1 8}}$ y pusieron en marcha el Instituto Caro y Cuervo, donde se ejecutaron proyectos idiomáticos, filológicos y lingüísticos. Su organización académica y administrativa convirtió a esta especialización en una verdadera formadora de intelectuales, quienes contribuyeron al conocimiento y rescate del patrimonio histórico y cultural del país. Desde los campos idiomático, lingüístico y filológico, brindó aportes para la construcción de la pretendida identidad nacional.

El bagaje académico adquirido fue utilizado para desarrollar investigaciones que abordaron las complejidades de un País en permanente ebullición. De tal manera, se obró en armonía con el pensamiento de Dewey como lo planteaba un estudiante de la Normal en su trabajo de grado, para él la escuela debía "enseñar al hombre a vivir una existencia más armoniosa con la sociedad, más rica de significados y más de acuerdo con la evolución progresista de la humanidad"19.

16. Ibíd. p. 86.

17. ESCUELA NORMAL SUPERIOR. Archivo Facultad de Ciencias de la Educación de la UPTC. Legajo 94. Folio 23.

18. Edilberto Cruz Espejo, "Directores del Instituto Caro y Cuervo. Historia del Departamento de Lexicografía", Thesaurus, vol. 49, (1999): 433.

19. Julio César Feuilleet, "La escuela Activa". Tesis de pregrado en la Licenciatura en Ciencias de la Educación en la Escuela Normal Superior en Bogotá, 1937, 13. 
En este orden de ideas, en estudios de corte histórico, etnológico, lingüístico y antropológico se recurrió a trabajos en el campo, al contacto directo con la realidad para recopilar datos y muestras que tras describirse y cotejarse con rigurosidad, conducían a la obtención de valiosos hallazgos.

Para todas las investigaciones la biblioteca de la Normal Superior fue un recurso fundamental, pues la diversidad de textos que conformaban sus colecciones, permitió efectuar consultas rigurosas y analizar diversos materiales documentales: "era la mejor en ese momento, técnicamente superior a la Biblioteca Nacional, aunque no tuviera el mismo volumen de libros que ésta. Su organización era más técnica, lo que facilitaba el acceso a las obras"20. En la biblioteca se clasificaron y pusieron a disposición de los interesados obras de Ciencias Naturales, Sociología, Antropología, Historia, Geografía, Filosofía, Literatura y Artes, ya fueran libros, revistas o folletos, provenientes de instituciones nacionales (como las administraciones y gobernaciones regionales y locales) e internacionales, publicadas en distintos países, entre ellos, Francia, Inglaterra, España, Estados Unidos, México, Argentina, Chile y Venezuela.

\section{EL INSTITUTO CARO Y CUERVO, DIFUSOR DE LOS ESTUDIOS EN FILOLOGÍA Y LINGÜÍSTICA, COMO APORTE A LA EDUCACIÓN Y LA CULTURA DEL PAÍS}

La creación del Instituto Caro y Cuervo, dedicado al cultivo y difusión de los estudios filológicos y lingüísticos, puede considerarse como una extensión del pensamiento científico y cultural de dos connotados intelectuales que hicieron historia en la vida académica del país: Rufino José Cuervo ${ }^{21}$ y Miguel Antonio Caro $^{22}$. Ambos promovieron la fundación de la Academia Colombiana de la Lengua desde 1870 y sobresalieron en su calidad de filólogos y escritores, participaron en distintos ámbitos culturales y dejaron obras de significativa trayectoria nacional. Como lo planteó el padre Félix Restrepo, uno de sus propósitos fue "continuar, entre otros varios trabajos científicos de gran aliento emprendidos en diversas épocas en nuestra patria, el interrumpido Diccionario de construcción y régimen de la lengua castellana del príncipe de nuestros filólogos"23.

El estudio de los asuntos relacionados con el idioma se llevó a cabo en Colombia desde finales del siglo XIX, por medio de trabajos que confirieron

\footnotetext{
20. Martha Cecilia Herrera y Carlos Low, Los intelectuales y el despertar cultural del siglo. El caso de la Escuela Normal Superior. Una historia reciente y olvidada (Bogotá: Imprenta Nacional, 1994), 34-39

21. El interés por los estudios gramaticales e inquietudes humanísticas del filólogo Don Rufino José Cuervo, nacido en Bogotá en 1844 y murió en París en 1911, ciudad donde se radicó desde 1882.

22 Su inclinación hacia la escritura, la literatura y la poesía de Miguel Antonio Caro provino de su hogar natal bogotano, pues fue hijo del poeta José Eusebio Caro.

23. Félix Restrepo, "Para la historia”, Thesaurus, vol. 1, (1945): 2.
} 
gran importancia a las lenguas vivas, la filología hispanoamericana y la investigación lingüística. Tal actividad correspondió a un interés generalizado en toda Latinoamérica con el fin de conocer e investigar las letras, tareas para las cuales se siguió el modelo de la Real Academia de la Lengua Española, creada en 1713 en el reinado de Felipe V. Esta institución se convirtió en líder de la política que sustentaba la unidad del idioma, a través del estudio y difusión del diccionario y la gramática.

Durante el Gobierno de Eduardo Santos (1938-1942), Jorge Eliécer Gaitán en su calidad de Ministro de Educación, en 1940 se creó El Ateneo Nacional de Altos Estudios, lo cual significó un cambio fundamental en la manera de conocer y difundir el estudio de las letras. En efecto, entre sus metas estuvieron la conservación de la tradición científica nacional, la continuación de las investigaciones de la Expedición Botánica y la Comisión Corográfica, y la realización de trabajos filológicos y lingüísticos ${ }^{\mathbf{2 4}}$.

Esta fue una gestión fructífera, efectuada conjuntamente entre la Academia y el Gobierno nacional, pues el proyecto que después se convirtió en la Ley fundacional, se logró "gracias al apoyo de los ministros de Educación Nacional Guillermo Nannetti y Germán Arciniegas, el Director de Extensión Cultural y Bellas Artes, Darío Achury Valenzuela, y Don Tomás Rueda Vargas"25.

Al comentar este suceso, el destacado intelectual alemán Gunther Schütz aprovechó para recordar el renombre cultural de Bogotá:

No es por casualidad el que una entidad tal se haya creado precisamente en Colombia. Este país puede jactarse de un gran esplendor humanístico durante el siglo XIX, el que le valió a su capital la reputación de la Atenas Suramericana. El Instituto ve una de sus tareas más nobles justamente en el comentario, la propagación y la complementación de las obras de los dos pensadores excelsos, el del latinista, historiador, crítico literario y bibliógrafo Miguel Antonio Caro y el del lingüista, Rufino José Cuervo ${ }^{26}$.

En la estructura del instituto, en forma paulatina, fueron apareciendo departamentos especializados: Lexicografía, Dialectología, Biblioteca, Historia Cultural, Lingüística General, Lingüística Indígena y Literatura Hispanoamericana. Asimismo, contó con el Seminario Andrés Bello, sección dedicada a la formación de pensadores colombianos y extranjeros, cuyo trabajo le granjeó un merecido reconocimiento internacional.

24. Un hecho significativo fue la apertura en 1942 de la Plazuela de San Carlos en Bogotá, espacio construido en homenaje a Rufino José Cuervo. Germán Arciniegas, "Instituto Caro y Cuervo", Indias. Archivo General de la Nación. Bogotá, 1942, 3-3.

25. Félix Restrepo, "Para la historia”, Thesaurus, vol. 1, (1945): 3-4.

26. Gunther Shütz, "El mayor centro de investigación y enseñanza filológico-lingüística en Hispanoamérica: el Instituto Caro y Cuervo de Bogotá”, Noticias Culturales. No. 76 (1967): 17. 
El Ateneo contaba con un Director Honorario, un Director-Profesor, un Investigador, un Técnico y tres auxiliares ${ }^{27}$. Entre las funciones del director como profesor estaba la de dirigir las clases de latín y griego. El primer Director Honorario del Instituto fue el padre Félix Restrepo (1887-1965) ${ }^{28}$, en esa época Rector de la Universidad Javeriana. Fue una de las personalidades más destacadas e influyentes de nuestra patria durante los últimos decenios: notable filólogo, escritor, humanista, helenista, letrado, pedagogo, orador y célebre sacerdote.

La relación del Instituto con la Escuela Normal Superior fue muy significativa, en especial, con el trabajo de Pedro Urbano González de la Calle, quien llegó a Colombia en calidad de exiliado español en 1939 y permaneció en Colombia hasta 1949. El profesor Urbano contribuyó con las cátedras de Lingüística general, latín, Gramática histórica del Castellano y Sánscrito ${ }^{29}$ y dictó conferencias en la Escuela Normal Superior. A su vez, el Instituto contó con un equipo de la más alta categoría: "los señores Julián Motta Salas, Rafael Torres Quintero, Francisco Sánchez Arévalo y la colaboración de la señora Cecilia Hernández de Mendoza"30.

Los forjadores del Instituto entendieron que la prolongación de las labores emprendidas sólo se aseguraba con la formación de un personal idóneo y capacitado para abarcar con suficiencia cada uno de los frentes de acción.

El padre Félix Restrepo y su colaborador Pedro Urbano González de la Calle asumieron la enseñanza de diferentes áreas afines al lenguaje. Inicialmente abordaron la gramática e historia de las lenguas griega, castellana y sanscrita, además de las nociones requeridas para estudiar el español en América. Al ser la cátedra otro medio para difundir los estudios filológicos, se organizaron clases destinadas a un público abierto, entre ellas, una dedicada al análisis del castellano empleado en Bogotá. Lo anterior muestra que en la docencia se vio una oportunidad para extender el conocimiento a individuos que sin pertenecer a la planta de funcionarios, mostraban interés por acercarse a la cultura lingüística. ${ }^{31}$

Por el Decreto 786 de 1944, destinado a organizar las finalidades de la institución, su planta administrativa y la publicación del Boletín. Igualmente,

27. El Director-profesor con un salario de $\$ 300.00$ mensuales, un colaborador técnico, $\$ 250.00$, un investigador de lingüística colombiana, $\$ 300$.oo, tres auxiliares escogidos por concurso, cada uno con un salario de $\$ 200$, uno de los cuales desempeñará el oficio de secretario.

28. El padre Félix Restrepo nació en Medellín el 23 de marzo de 1887 y murió en Bogotá el 16 de diciembre de 1965.

29. Félix Restrepo, «Varia», Thesaurus, Tomo XX. No. 3 (1965): 653.

30. Ibíd., 2

31. ARCHIVO GENERAL DE LA NACIÓN, "Historia Instituto Caro y Cuervo. Labores docentes e investigación Doctrinal", Cultura (1940): 3. 
con la autorización del Ministerio de Educación, desarrollaron investigaciones lingüísticas y filológicas.

El Ateneo continuó su marcha y en 1947 además contaba con un personal selecto de las mejores calidades humanas: José Manuel Rivas Sacconi, profesor de Filosofía y Letras, al igual que los doctores Rafael Torres Quintero y Fernando Torres Martínez, ambos graduados en la Universidad Javeriana, y los Licenciados Luis Flórez, Eduardo Amaya y Francisco Sánchez Arévalo, provenientes de la Normal Superior. Jorge Páramo con su obra constituye un estudio de la dialectología, siendo su aporte el manual de la novela colombiana, siglos XIX y XX, en su libro Evolución de la novela en Colombia. Este equipo se enfocó en dar continuidad y optimizar los estudios humanísticos, que en Colombia corrían el riesgo de desaparecer. ${ }^{32}$

Dentro del profesorado se designó al investigador José Manuel Casas Manrique como investigador de lingüística colombiana, cuyas funciones eran: estudiar las lenguas de los pueblos aborígenes del país; elaborar gramáticas y vocabularios modernos de estas; preparar ediciones críticas sobre distintos aspectos del idioma, como también catecismos y sermonarios de escritores antiguos, entre otras tareas.

Durante la presidencia de Mariano Ospina Pérez y Mario Carvajal como Ministerio de Educación, el Ateneo experimentó una reorganización. De acuerdo con el Decreto 726 de febrero 28 de 1947 se determinó la conveniencia de otorgarle autonomía "para el pleno logro de sus finalidades, en consonancia con sus peculiaridades"33. El Gobierno nacional promulgó la resolución $1^{\text {a }}$ del 24 de febrero de 1949, para organizar las secciones de Lexicografía y Dialectología, encargadas de proseguir con la construcción del "Diccionario" y transcripción de material bibliográfico. Para apoyar estos procesos, expidió la Resolución 2 del 20 de octubre de 1949, cuyo propósito era nombrar un personal especializado en dichas áreas.

Estas modificaciones conllevaron una nueva fase, ya sin la orientación titular del padre Restrepo, pues luego de guiar los destinos del distinguido organismo durante ocho años, desde su origen como dependencia del Ateneo de Altos Estudios, y de haber impregnado su espíritu y dinamismo a tan admirable obra, el eclesiástico vio la pertinencia de implementar un relevo y presentó su renuncia el 26 de julio de 1948.

El Profesor Rivas Sacconi (1917-1991) había ejercido el cargo de secretario general. ${ }^{34}$ “[...] empezó a trabajar por horas en la continuación del Diccionario

32. MINISTERIO DE EDUCACIÓN NACIONAL. "Instituto Caro y Cuervo", Boletín Instituto Caro y Cuervo, Tomo III. Números 1, 2 y 3, ( 1947): 362-363.

33. Este Decreto se publicó en el número 26383 del Diario Oficial, del jueves 20 de marzo de 1947.

34. Edilberto Cruz Espejo, "El Instituto Caro y Cuervo. Historia del departamento de Lexicografía", Thesaurus: Boletín Instituto Caro y Cuervo, Tomo 49, No. 2 (1999): 432. 
de Construcción y Régimen de la Lengua Castellana y a realizar otros estudios filológicos"35. Luego se convirtió en uno de los colaboradores hasta 1982. Tan prolongada permanencia indica su dedicación a esta tarea, a la cual entregó "gran parte de su vida, inteligencia, vocación intelectual y capacidad de liderazgo. Fue el más grande gestor de esta empresa cultural de Colombia, hasta convertirla en un centro cultural universal"36.

Asimismo, Rivas Sacconi, planteó que la filosofía de la institución como tal: "Es una obra que se edifica con espíritus, antes que con elementos materiales. No es, no puede ser una sección administrativa, despersonalizada [...] diría que es una congregación de hombres aunados por ideales y aficiones comunes, tendidos en un esfuerzo de superación. Es una obra del espíritu para la cultura nacional y universal" 37 .

En cuanto a la consolidación de la bibliografía, se hizo necesario avanzar en la colección de autores nacionales e internacionales, como uno de los grandes aportes a la constitución de un sólido centro de consulta. En la dirección de Rivas Sacconi se definieron los lineamientos pertinentes para que dicho espacio prestara un servicio de calidad a quienes lo visitaran en el transcurso de sus investigaciones. Allí se dio inicio a la catalogación de obras que incidieron en el desarrollo del conocimiento de la literatura universal y colombiana.

El primer director de la Biblioteca [...] fue el doctor Jorge Páramo Pomareda. La Biblioteca ya poseía un cierto número de ejemplares: 8300. En 1950 aparece la primera reglamentación para su funcionamiento. Don Carlos Valderrama Andrade colabora en ella, catalogando y clasificando gran parte de los libros. Posteriormente se nombró director a Rubén Pérez Ortiz ${ }^{38}$.

Esta sección logró mantener un constante movimiento de adquisición e intercambio de material bibliográfico ${ }^{39}$, dinámica que le otorgó acceso a importantes publicaciones en las áreas relacionadas con los horizontes de

35. Ibíd., 433.

36. Ibíd., 386.

37. "Creación, estatutos, proyectos y avances de la Sociedad Colombiana Lingüística Aborigen" (Colombia 1943), INSTITUTO ETNOLÓGICO NACIONAL, Archivo Histórico Instituto Etnológico Nacional, Bogotá, Caja 4 Carpetas 1 y 2. Folios 5-2.

38. INSTITUTO CARO Y CUERVO, "Segunda época del Instituto Caro y Cuervo", Noticias Culturales, 31 (1987): 4.

En este año, el Instituto contaba con cerca de 3700 libros. En este año entraron 850 obras de diferentes autores, de la cuales 630 por compra, por un valor total de $\$ 4865.80$; y 220 por canjes y donaciones. INSTITUTO CARO Y CUERVO, "Memorias del director del Instituto Caro y Cuervo", Thesaurus, Boletín del Instituto Caro y Cuervo, 483.

39. "En este año, el Instituto contaba con cerca de 3700 libros. En este año entraron 850 obras de diferentes autores, de la cuales 630 por compra, por un valor total de \$4865.80; y 220 por canjes y donaciones". INSTITUTO CARO Y CUERVO. "Memorias del director del Instituto Caro y Cuervo", Thesaurus, Boletín del Instituto Caro y Cuervo (1951): 483. 
trabajo institucionales. Para coordinar de una manera centralizada estos procedimientos, en 1950 se creó la División Bibliográfica.

Para 1951 la planta administrativa registraba un crecimiento. Además del Director, se crearon los cargos de Subdirector y Presidente, y se nombró como Director de la Sección de Dialectología a Luis Flórez; como Bibliotecario a Jorge Páramo Pomareda; y Auxiliares, como Oficial de Correspondencia, a Margarita Villarreal Niño; y Ayudante de Administración, a Dalia Maritza Ramírez ${ }^{\mathbf{4 0}}$.

Desde 1949 se habían fortalecido las secciones de Lexicografía y Dialectología, se había incrementado y clasificado la Biblioteca con temas de la cultura colombiana; aparecieron los volúmenes IV y $\mathrm{V}$ de las publicaciones del Instituto, y se realizó la preparación del tomo de homenaje al Ex-Director Honorario, padre Félix Restrepo.

Después de Rivas Sacconi, otros importantes directores fueron Rafael Torres Quintero ${ }^{41}$ e Ignacio Chaves Cuevas ${ }^{42}$, quienes lograron afianzar al Instituto como la empresa lingüística y cultural más importante no sólo de Colombia, sino del mundo hispánico. Todos ellos, hombres de estudio y acción, fueron el alma de los proyectos; de hecho, las metas y distinciones no se habrían obtenido sin su liderazgo y persistencia.

En sus talleres operó la imprenta denominada "La Patriótica", fundada en 1960, ingenio tipográfico que poseía el mismo nombre de aquel adquirido por Antonio Nariño en 1791 y en el cual se imprimió el "Papel Periódico de Santafé de Bogotá", al igual que la famosa traducción de los "Derechos del Hombre y del Ciudadano".

Finalmente, vale la pena señalar que uno de los aportes de tipo cultural más significativos fue la difusión del conocimiento y patrimonio de la literatura colombiana, y como parte de las noticias culturales del Instituto Caro y Cuervo, la creación y continuidad de la revista Thesaurus, los libros, los folletos, los trabajos científicos e investigadores de docentes y alumnos al desarrollar proyectos debidamente aprobados en el Instituto Caro y Cuervo.

El cultivo de la investigación científica en las áreas de la lingüística, la filología, la literatura, las humanidades y la historia cultural colombiana se

40 Ibíd., p. 486.

41. Rafael Torres Quintero nació en Santa Rosa de Viterbo, Boyacá, el 5 de noviembre de 1909. En 1943 obtuvo el título de Doctor en filosofía y letras. En 1944 accedió al cargo de investigador sobre las obras de Cuervo, puesto que ocupó por concurso. En 1949 desempeñó la cátedra de latín en el colegio Nuestra Señora del Rosario, de literatura y lingüista en la Universidad Javeriana, en la Universidad Pedagógica y en la Gran Colombia, y la de Castellano en la Escuela Normal Superior.

42. Ignacio Chaves Cuevas nació en Bogotá el 18 de abril de 1938, bachiller del Colegio Agustiniano. Estudió filosofía y letras en la Universidad de Los Andes, se especializó en literatura en Florencia, Italia, en la Universidad Complutense, fue catedrático en la Universidad de Florencia, Italia, y en Colombia en la Universidad Nacional, la Universidad Santo Tomas, la Universidad de Los Andes, Universidad Javeriana, entre otras. 
convirtió en el objetivo primordial del Instituto, su filosofía y cometido. De hecho, se había enriquecido el patrimonio idiomático nacional, promovido el uso adecuado del lenguaje y se había oficiado como órgano asesor en diversos contextos que requerían un manejo impecable de la comunicación oral y escrita.

Esta vigencia había sido posible gracias al continuo fortalecimiento de la misión trazada desde un comienzo:

La misión del Instituto fue primordialmente descubrir y fomentar la vocación de los que se sentían llamados a los estudios filológicos, darles la oportunidad y los medios de cultivar y revelar sus aficiones, reunir y encauzar múltiples capacidades en una empresa común. Esta finalidad fue vista claramente por quienes bosquejaron por vez primera la creación del Instituto, al decir que este se erigiría con el objeto de formar especialistas en Filología y Lingüística, con miras a continuar la tradición nacional en estas disciplinas ${ }^{43}$.

En cuanto al programa académico se exponían cursos regulares pero además se aprovechó la presencia en el país de profesores internacionales para inaugurar en 1949 el taller sobre Dante Alighieri y sus obras, dictado por Carlos Bruscantini, experto en lenguas y literatura clásica. Testimonio de ello fue otro curso del mismo año, encomendado al Doctor José María Restrepo Millán, cuyo tema general fue "Valores idiomáticos, artísticos y legendarios de La Eneida, de Virgilio". A su vez, los integrantes y colaboradores del Instituto realizaron seminarios y encuentros, siempre con el interés de proporcionar elementos que facilitaran el cumplimiento de las distintas funciones y robustecieran la gestión.

Así, se ofrecieron cursos tal como se ejemplifica en 1949, la cual contaron con una intensidad horaria y un docente encargado cuya característica del curso es la calidad del docente, su formación y su origen para impartir este tipo de formación y la importancia en mayor grado que se da a la enseñanza del griego en este instituto, como se especifica a continuación:

- Griego, 3 horas semanales, profesor Francisco María Rengifo

- Alemán, 2 horas, profesor Paul Essabal

- Árabe, 1 hora, profesor Paul Essabal

- Lingüística indoeuropea, profesor Paul Essabal

- Fonética Española, 1 hora, profesor Luis Flórez ${ }^{44}$.

43. Rivas Sacconi José. "Informe del director del Instituto Caro y Cuervo al Ministerio de Educación Nacional”, ICCC, Banco de la República, 1951, 4.

44. Rivas Sacconi José, "Informe del director del Instituto Caro y Cuervo al Ministerio de Educación Nacional", 1949, 20. 
El director Rivas Sacconi siguió la línea de su predecesor y comprendió la importancia de acrecentar la formación en los temas afines a la lengua castellana y su historia, al igual que en las técnicas de investigación filológica. Por tanto, durante su administración dio un impulso decisivo a la tarea educativa. En este sentido, junto a las clases presenciales, él mismo estuvo al frente de una cátedra radial en 1951: "Invitado por la Radiodifusora Nacional, el Director del Instituto mantuvo desde julio de este año, un curso sobre autores italianos en la sección de Reseña Crítica de la mencionada estación"45.

Junto a los mencionados directores, cabe resaltar el quehacer docente de algunos eminentes colaboradores: González de la Calle explicó con verdadera consagración el sánscrito, materia en la que era una verdadera autoridad; Francisco María Rengifo, reconocido profesor de latín, filosofía y griego, enseñó este último idioma con suma excelsitud en 195046; los académicos Francisco Sánchez Arévalo y Rafael Torres Quintero, sobresalieron como dos de los más connotados maestros: "Durante su largo tiempo de actividades docentes se distinguieron uno y otro por su consagración y laboriosidad"47.

Así mismo, la investigación y extensión en el Instituto se destacó por impulsar la práctica investigativa, pues comprendió que por este conducto podía reconocer y divulgar diversas dimensiones del patrimonio lingüístico nacional, con lo cual corroboraba su naturaleza de centro de altos estudios. Por lo tanto, desde su creación, sus miembros emprendieron los procesos pertinentes para desarrollar los trabajos comisionados, hacer investigación y extensión.

En lo concerniente a la construcción del "Diccionario", redactaron papeletas lexicográficas desde la $\mathrm{L}$ hasta la $\mathrm{Z}$ con el fin de registrar en ellas las formas y particularidades más autorizadas e interesantes que estuvieran contenidas en las obras literarias y científicas de las letras españolas, aparecidos desde los orígenes del idioma hasta aquel momento de mediados del siglo XX. Al recoger este material, el Director y los colaboradores anotaban cuantas curiosidades históricas, arqueológicas, lingüísticas y filológicas descubrían en los textos examinados. Todo este enorme caudal de información fue también aprovechado en la elaboración de índices bibliográficos de indigenismo y dialectología, en obras referentes a la gramática histórica del castellano, de lingüística y filología románicas, e incluso, en libros de texto sobre literatura.

Al final, el "Diccionario" se convirtió en la obra monumental que otorgó el mayor reconocimiento en el mundo de habla hispana. Para 1951, la

45. Ibíd., 485.

46. Rengifo, Francisco. "El Instituto Caro y Cuervo", Thesaurus: Boletín del Instituto Caro y Cuervo. No. 1, 2, 3 (1959): 365.

47. INSTITUTO CARO Y CUERVO. "Veinticinco años de labores de Rafael Torres Quintero y Francisco Sánchez Arévalo”. Thesaurus. Boletín del Instituto Caro y Cuervo. No. 3 (1965): 666. 
Organización de Estados Americanos (OEA) se había enterado de este encargo y ofreció su apoyo para la terminación de tan magno esfuerzo, colaboración que fue muy valorada por la dirección del Instituto:

Otro hecho de gran importancia para el adelantamiento de los trabajos del Diccionario de Cuervo han sido los pasos dados por la OEA para concretar su ayuda a la terminación de dicha obra, en cumplimiento de las resoluciones aprobadas por las Conferencias Interamericanas de la Habana en 1928 y en Bogotá $1948^{48}$.

Precisamente, la proyección de este Instituto fue el Seminario instituido en 1958 con el propósito de promover la educación superior en las áreas de lingüística, literatura del español y cultura hispanoamericana, y que tomó el nombre de Andrés Bello. Surgido gracias a un convenio firmado con la OEA, se convirtió en un programa de extensión donde se forman estudiantes e investigadores de diversas procedencias. "La lengua castellana que de Nebrija a Bello no ha tenido precisamente los cuidados que había menester para curar su descaecimiento, halla en este espacio su altar y su taller"49.

Del Instituto Caroy Cuervo es significativo resaltar dos obras monumentales: el Atlas lingüístico y etnográfico de Colombia, único atlas en este género que abarca casi la totalidad de un país hispanohablante, el cual fue dirigido por don Luis Flórez y José Joaquín Montes, editado en 1982 y premiado con la Orden Nacional al Mérito. La segunda es el Diccionario de construcción y régimen de la lengua castellana, obra cumbre de la filología hispanoamericana, reunida en 8 tomos. Con palabras de nuestro nobel Gabriel García Márquez, es una novela de palabras. De allí que para el Instituto Caro y Cuervo fuera prioritaria la terminación de este proyecto filológico colombiano.

Igualmente, es significativo señalar que este Instituto recibió el galardón a la Lengua Española, Príncipe de Asturias, en 1999, por su labor cultural, social y humana realizada por personas y equipos de trabajos en el ámbito internacional, principalmente en el de las naciones pertenecientes a la comunidad iberoamericana ${ }^{50}$.

Asimismo, se propiciaron vínculos con entidades extranjeras que, a semejanza del Instituto, se basaron en el trabajo de afamados lingüistas para desarrollar su labor. Tal fue el caso de "la cooperación establecida entre el Instituto y la Comisión Editora de las Obras Completas de Andrés Bello (1781-

48. Rivas Sacconi José, "Memoria del director del Instituto Caro y Cuervo sobre las labores realizadas”, 1951, 476.

49 INSTITUTO CARO Y CUERVO, "El Instituto Caro y Cuervo". Thesaurus: Boletín del Instituto Caro y Cuervo. No. 1, (1999): 278.

50. Mireya Cisneros. "Departamento de Lingüística del Instituto Caro y Cuervo", Thesaurus: Boletín Instituto Caro y Cuervo, 1996, 1-2. 
1865)"51, autor considerado es uno de los grandes humanistas y "crítico literario" de Latinoamérica. La Comisión Editora sede en Caracas tiene el carácter de difusora así trabaja en forma admirable para reunir, fijar y publicar todos los escritos del gran maestro venezolano ${ }^{52}$. Esta Comisión se interesó en las tareas realizadas por la entidad colombiana y entre ambas se creó una fluida retroalimentación. Con el intercambio se le "infundió un carácter innovador, aplicándole al mismo tiempo los principios científicos de la lingüística"53.

Finalmente, dentro de sus proyecciones el Instituto Caro y Cuervo otorgó hasta 1980 títulos de especialización, y a partir de 1983 comenzó a ofrecer dos programas de Maestría: uno en Lingüística Hispánica y otro en Literatura Latinoamericana y ha ofrecido un Diplomado en Literatura, además de una vasta oferta de formación para el trabajo, hecho que evidencia el legado del patrimonio histórico cultural y pedagógico para la construcción de la nación colombiana.

Los aportes de Luis Flórez (1916-1985) fueron significativos. Como profesional egresado de la Normal Superior, se adentró en las particularidades del uso del idioma en distintas regiones del país y socializó sus hallazgos en publicaciones como el libro La pronunciación del español en Bogotá y el ensayo "El habla del Chocó". Este ambicioso proyecto pretendía cubrir la mayoría del territorio nacional, de ahí que en 1951 se planteaba su continuidad; es decir: "la posibilidad de un viaje al Departamento de Antioquia, con el fin de complementar el estudio directo del idioma que allí se habla"54.

Otro aspecto a resaltar son los escritos inéditos de Cuervo encontrados en Biblioteca Nacional, los cuales fueron totalmente restaurados, entre ellos: "Castellano popular y literario", "Las segundas personas del plural en las conjugaciones castellanas", y "Disquisiciones sobre antigua ortografía y pronunciación castellanas". Además, se estudiaron y publicaron volúmenes sobre otros nombres de las letras patrias, como Marco Fidel Suárez, José Manuel Marroquín, al tiempo que se indagaron temáticas e interrogantes en el terreno de la lingüística, la lexicografía y la filología. Para 1951, el Instituto había incrementado su comunicación bibliográfica con numerosas entidades internacionales de objetivos semejantes a los suyos ${ }^{55}$.

51. Andrés Bello nació en Caracas en 1781, Bachiller en Artes, estudió en la Universidad de Caracas, de tendencia religiosa católica. Luis Bocaz y Jorge Ramírez, Andrés Bello: una biografía cultural. Santafé de Bogotá: Convenio Andrés Bello, 2000, 9-14.

52 José Rivas Sacconi, “Thesaurus” Boletín Instituto Caro y Cuervo. Bogotá, Tomo VII, 22.

53. Ibíd., 22.

54. Ibíd.

55. INSTITUTO CARO Y CUERVO. “Canje de revistas con el Instituto Caro y Cuervo”, Thesaurus: Boletín Instituto Caro y Cuervo. Bogotá, Tomo VII. Números 1, 2 y 3 (1951): 489-490. 
De gran trascendencia para el nombre de Colombia y para la difusión de su cultura en el mundo, ha sido la creación de la filial argentina del Instituto Caro y Cuervo, con tres finalidades inmediatas: a) acercamiento cultural entre Colombia y la Argentina; b) facilitación de las investigaciones literariofilológicas, y c) difusión de la bibliografía especializada en Colombia y en la Argentina ${ }^{56}$.

La constitución de este centro en la ciudad de Buenos Aires facilitó la conformación de una biblioteca colombiana especializada, al tiempo que permitió ofrecer intercambios académicos, por medio de becas, para jóvenes argentinos deseosos de estudiar en la Escuela Normal Superior.

\section{CONCLUSIONES}

La relación de maestros y estudiantes de la licenciatura en Filología e Idiomas de la Escuela Normal Superior estuvo ligada a la obra de los egresados de la Escuela Normal Superior y de la Colaboración de profesores de Instituto Caro y Cuervo en la Normal como es el caso del profesor Pedro Urbano González de la Calle. Los profesores Licenciados Luis Flórez, Eduardo Amaya y Francisco Sánchez Arévalo eran provenientes de la Normal Superior. El maestro Luis Flórez en su fecunda producción, llevó a cabo con sus investigaciones, por una parte, el conocimiento de la realidad lingüística nacional, con base en la observación directa del habla popular sin ánimo correctivo y, por otra parte, difundió masivamente entre el público, por medio de publicaciones y notas de prensa, indicaciones atinentes al buen uso de la lengua, con un criterio flexible, moderno y cercano a la población, alejado del purismo recalcitrante y pedante de épocas previas.

El Instituto también tuvo la tarea de hacer canje de obras desde su sección de la Biblioteca, para continuar este intercambio iniciado con la revista Thesaurus y, de este modo, dar a conocer las diferentes investigaciones y motivar un diálogo con diversas comunidades académicas.

Los resultados de las investigaciones, las metodologías empleadas en ellas, las recomendaciones de los autores y los aportes al conocimiento se plasmaban en libros y artículos que daban cuentan de todos estos pormenores. El Instituto, de acuerdo con su política de indagación, recopilación y divulgación del patrimonio bibliográfico del país, publicó numerosos trabajos y contribuyó así a expandir la cultura del libro y la lectura entre la población. Al mismo tiempo, las ediciones críticas sobre materias especializadas enriquecieron la discusión disciplinar y proporcionaron nuevos referentes para posteriores estudios emprendidos por expertos del idioma.

56 Rivas Sacconi José, "Memoria del director del Instituto Caro y Cuervo sobre las labores realizadas”, $1951,21$. 
Los aportes a la cultura del país trascendieron en la magna obra del Instituto Caro y Cuervo, como vigía y difusor del pensamiento en las letras desde el soporte de la filología y los idiomas.

La formación de los educadores en la licenciatura en Filología e Idiomas de la Escuela Normal Superior en Bogotá se convirtió en reto para las generaciones que se formaron allí y luego se especializaron en el Instituto Caro y Cuervo bajo el lema de la "alta cultura", realmente es un hecho sin precedentes este tipo de formación, pues el educador conoció un sinnúmero de obras, conoció saboreó las bibliotecas, los clásicos de la literatura y una infinidad de obras en varios idiomas, este profesional formado en esta época era conocedor y comprendía más de dos idiomas.

Es significativo seguir trabajando en estas temáticas en el concierto de la historia de la educación y profundizar en las investigaciones principalmente en el talento humano de estas dos instituciones y su proyección, los cuales formaron una generación de intelectuales de altas calidades científicas y humanísticas.

\section{REFERENCIAS BIBLIOGRÁFICAS}

ARCHIVO GENERAL DE LA NACIÓN, “Historia Instituto Caro y Cuervo. Labores docentes e investigación Doctrinal", Cultura, (1940): 3.

ESCUELA NORMAL SUPERIOR. Archivo Facultad de Ciencias de la Educación de la UPTC, Legajo 37. Folio 203. ESCUELA NORMAL SUPERIOR. Archivo Facultad de Ciencias de la Educación de la UPTC. Legajo 94. Folio 23. ESCUELA NORMAL SUPERIOR. Archivo Facultad de Ciencias de la Educación de la UPTC, Legajo 103. Folio 46. ESCUELA NORMAL SUPERIOR. Archivo Facultad de Ciencias de la Educación de la UPTC. Legajo 100. Folio 576.

ESCUELA NORMAL SUPERIOR Archivo Facultad de Ciencias de la Educación de la UPTC. Legajo 103. Folio 45

Legajo 23. Folio 17. Programa de francés/Sección de Filología e Idiomas, primer año 1937.

Legajo 43. Folio 79. Correspondencia dirigida al Rector de la Escuela Normal Superior en 1939. Seminario de Cultura americana, 1937. Carta enviada a William Barrien por Lisandro Medrano, diciembre 16 de 1943. 
Comunicado enviado a Gerard Mashur por José Francisco Socarrás Rector octubre 11 de 1938, Legajo 36. Folio 301.

INSTITUTO ETNOLÓGICO NACIONAL, Archivo Histórico Instituto Etnológico Nacional, Bogotá, Caja 4 Carpetas 1 y 2 . Folios 5 - 2.

INSTITUTO CARO Y CUERVO, “Segunda época del Instituto Caro y Cuervo”, Noticias Culturales, 31, (1987): 4.

En este año, el Instituto contaba con cerca de 3700 libros. En este año entraron 850 obras de diferentes autores, de la cuales 630 por compra, por un valor total de $\$ 4865.80$; y 220 por canjes y donaciones.

INSTITUTO CARO Y CUERVO, "Memorias del director del Instituto Caro y Cuervo", Thesaurus, Boletín del Instituto Caro y Cuervo, 483.

INSTITUTO CARO Y CUERVO, “Creación, estatutos, proyectos y avances de la Sociedad Colombiana Lingüística Aborigen". (Colombia 1943).

INSTITUTO CARO Y CUERVO. "Memorias del director del Instituto Caro y Cuervo", Thesaurus, Boletín del Instituto Caro y Cuervo. (1951): 483

INSTITUTO CARO Y CUERVO. "Veinticinco años de labores de Rafael Torres Quintero y Francisco Sánchez Arévalo". Thesaurus. Boletín del Instituto Caro y Cuervo. No. 3, (1965): 666.

INSTITUTO CARO Y CUERVO. “Canje de revistas con el Instituto Caro y Cuervo", Thesaurus: Boletín Instituto Caro y Cuervo. Bogotá, Tomo VII. Números 1, 2 y 3, (1951): 489-490.

INSTITUTO CARO Y CUERVO, "El Instituto Caro y Cuervo". Thesaurus: Boletín del Instituto Caro y Cuervo. No. 1, (1999): 278.

MINISTERIO DE EDUCACIÓN NACIONAL. Legajo 106. Folio 497. Decreto número 527 de 1946 (febrero 15). Listado de profesores de la Escuela Normal Superior en Bogotá, 1939. Oficio enviado al señor Guillermo Nannetti por Arthur J. Montaque, noviembre 17 de 1945.

MINISTERIO DE EDUCACIÓN NACIONAL. "Instituto Caro y Cuervo", Boletín Instituto Caro y Cuervo, Tomo III. Números 1, 2 y 3, (1947): 362-363.

Decreto número 1218 de 1938 (julio 9).

Decreto se publicó en el número 26383 del Diario Oficial, del jueves 20 de marzo de 1947.

Edilberto Cruz Espejo, “Directores del Instituto Caro y Cuervo. Historia del Departamento de Lexicografía”, Thesaurus, vol. 49, (1999): 433.

Edilberto Cruz Espejo, "El Instituto Caro y Cuervo. Historia del departamento de Lexicografía”, Thesaurus: Boletín Instituto Caro y Cuervo, Tomo 49, No. 2, (1999): 432.

Félix Restrepo, "Para la historia”, Thesaurus, vol. 1, (1945): 2.

Félix Restrepo, «Varia», Thesaurus, Tomo XX. No. 3, (1965), 653.

Germán Arciniegas, “Instituto Caro y Cuervo”, Indias. Archivo General de la Nación. Bogotá, 1942, 3-3

Gunther Shütz, "El mayor centro de investigación y enseñanza filológico-lingüística en Hispanoamérica: el Instituto Caro y Cuervo de Bogotá", Noticias Culturales. No. 76, (1967), 17.

Henry Bradley, The Making of English. (London: MacMillan, 1937), 5.

Julio César Feuilleet, "La escuela Activa". Tesis de pregrado en la Licenciatura en Ciencias de la Educación en la Escuela Normal Superior en Bogotá, 1937, 13.

José Rivas Sacconi, “Thesaurus” Boletín Instituto Caro y Cuervo. Bogotá, Tomo VII, 22

José Francisco Socarrás, Facultad de Educación y Escuela Normal Superior: Su Historia y aporte Científico, Humanístico y Educativo. (Tunja: La Rana y el Águila, 1987), 33. 
Martha Cecilia Herrera y Carlos Low, Los intelectuales y el despertar cultural del siglo. El caso de la Escuela Normal Superior. Una historia reciente y olvidada. (Bogotá: Imprentan Nacional, 1994), 49- 50.

Ministerio de Educación Nacional en la Resolución 576 de septiembre 5 de 1938.

Martha Cecilia Herrera y Carlos Low, Los intelectuales y el despertar cultural del siglo. El caso de la Escuela Normal Superior. Una historia reciente y olvidada. (Bogotá: Imprentan Nacional, 1994), 34-39

Manuel Bonilla, Orientaciones literarias. (Ibagué: Tipografía Salesiana, 1936), 95.

Martha Cecilia Herrera y Carlos Low, Los intelectuales y el despertar cultural del siglo. El caso de la Escuela Normal Superior. Una historia reciente y olvidada. (Bogotá: Imprentan Nacional, 1994), 45.

Mireya Cisneros. "Departamento de Lingüística del Instituto Caro y Cuervo", Thesaurus: Boletín Instituto Caro y Cuervo, 1996, 1-2

Luis Bocaz y Jorge Ramírez, Andrés Bello: una biografía cultural. Santafé de Bogotá: Convenio Andrés Bello, 2000, 9-14.

Rengifo, Francisco. "El Instituto Caro y Cuervo", Thesaurus: Boletín del Instituto Caro y Cuervo. No. 1, 2, 3. (1959): 365.

Rivas Sacconi José, “Informe del director del Instituto Caro y Cuervo al Ministerio de Educación Nacional”, 1949, 20.

Rivas Sacconi José, “Memoria del director del Instituto Caro y Cuervo sobre las labores realizadas”, 1951, 476.

Rivas Sacconi José. "Informe del director del Instituto Caro y Cuervo al Ministerio de Educación Nacional”, ICCC, Banco de la República, 1951, 4.

Rivas Sacconi José, “Memoria del director del Instituto Caro y Cuervo sobre las labores realizadas”, 1951, 21. 